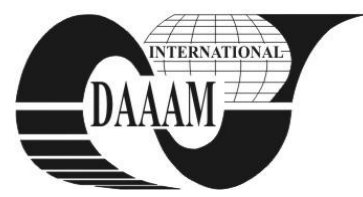

Annals of DAAAM for 2011 \& Proceedings of the 22nd International DAAAM Symposium, Volume 22, No. 1, ISSN 1726-9679 ISBN 978-3-901509-83-4, Editor B. Katalinic, Published by DAAAM International, Vienna, Austria, EU, 2011 Make Harmony between Technology and Nature, and Your Mind will Fly Free as a Bird Annals \& Proceedings of DAAAM International 2011

\title{
PROCESS MODELLING OF WASTE HEAT RECOVERY IN THE FOOD MANUFACTURING SECTOR
}

\author{
STURM, B[arbara]; SMITH, Thomas] R[obert]; JOYCE, S[haron] \& ROSKILLY, A[nthony] P[aul]
}

\begin{abstract}
The efficient use of energy within a manufacturing environment has become increasingly essential as the world strives towards a cleaner environment. With rising utilities costs and monetary incentives available for businesses looking towards a greener option, the search for additional process energy savings is gathering momentum. This paper describes the development of a model aiming to support small and medium sized companies (SME) in the British food sector to reduce their specific energy use in production by integrating existing thermal supply systems.
\end{abstract}

Key words: modeling, waste heat, food industry, efficiency

\section{INTRODUCTION}

The food and drink sector accounts for around $10 \%$ (approximately $42 \mathrm{TWh} / \mathrm{a}$ ) of the industrial energy use in the UK (HM Government, 2007). The potential savings achievable through efficient recovery of heat can be significant and has been estimated at $25 \%(2.8 \mathrm{TWh} / \mathrm{a})$ of the total recoverable waste heat in the UK (Muller et al., 2007; Reay \& Morrell, 2007). In addition, taking into account the number of similar processes within the same sector, most of the saving opportunities could be replicated from one production site to another.

Traditionally process integration is applied to increase efficiency in energy and materials use and to reduce emissions (Tuomaala et al. 2010). The performance of the heat exchanger network in a system is an important aspect of energy conservation. Its efficiency, flexibility, reliability and easy maintenance are very important issues. Furthermore, the methods to deal with pollution and emissions reduction including $\mathrm{CO}_{2}$ have received growing attention.

In food processing a huge amount of low grade thermal energy currently is wasted despite the fact that process temperatures mostly are relatively low themselves due to the heat sensitivity of bio-products processed. There is a wide range of recovery and upgrading technologies available but to date few have been applied (Ammar et al., 2011).

Current techniques for total site heat integration are generally based on steady state modelling and continuous operation (Dhole \& Linnhoff, 1993; Bandyopadhyay et al., 2010; Söderman \& Ahtila, 2010). Most of the manufacturing in the food industry is not continuous (Atkins et al., 2010). Therefore, for a reliable prediction of the effects of changing thermodynamic conditions by changing heat exchanging concepts, alternative concepts have to be applied.

Furthermore, thermal energy might be available at a time and place where it cannot be used directly, especially if the same production line is used to produce different products. So there is a need for energy stores to aid heat recovery within a batch environment (Atkins et al., 2010). Additionally plants which are adjacent can be linked to further improve efficiency of the system (Matsuda et al., 2009).

The principle of heat buses in the form of steam pipes has been applied for many years; however integration of systems by the use of additional lower temperature heat buses, especially for recovering low grade waste heat and refrigeration buses has not yet been explored.

The aim of the work presented here is to develop a working process model for a thermal bus system incorporating low grade waste heat from production, air compression system and refrigeration plants for optimum utilisation of primary energy. This is based on several case studies from different parts of the food sector.

\section{PROCESS ANALYSIS AND MODELING}

Several medium sized companies representing different parts of the food and drink manufacturing industry were selected to get a general overview of the sector.

All systems investigated have a common need for heating and refrigeration as well as air compression. In all cases, gas fed boilers are used to provide the full site heating demand for the processes as well as space heating. One of the most important aspects all cases have in common is both the irregularity of energy demand and availability of waste heat.

Tab. 1 gives an overview of heat sources in the different parts of the food sector. Most sources are identical in their nature. Similar temperature levels are to be expected.

Detailed energy audits were carried out for 5 companies. Based on the outcomes the most generally representative case was chosen as base case for the model.

Rather than applying pinch technology to a semi operational process; the maximum utility usage and therefore highest cost will be when the site is operating at full capacity. The heat exchanger network (HEN) needed to be designed in a way so it runs optimally during the standard operation as this period provides the largest process saving incentives.

Depending on the heat exchanger used, the minimum temperature difference between the warm and cold side $\Delta \mathrm{T}_{\text {min }}$ can vary and hence the maximum amount of heat that can be recovered.

The boiler operates in a continuous manner with the steam production. It is controlled to meet the constantly changing site heat demand. By attempting to recover heat from the process streams available, the load on the boiler can be further reduced during plant operation offering utility and emissions savings. When a stream is 'lost', the thermal demand will then be shifted back onto the boiler in accordance with the site steam demand.

\begin{tabular}{|l|c|c|c|c|}
\hline Sector & Beverage & Fruit & Savory & Dairy \\
\hline Air Compressor & $\mathrm{X}$ & $\mathrm{X}$ & $\mathrm{X}$ & $\mathrm{X}$ \\
\hline Boiler & $\mathrm{X}$ & $\mathrm{X}$ & $\mathrm{X}$ & $\mathrm{X}$ \\
\hline Evaporation & $\mathrm{X}$ & - & - & $\mathrm{X}$ \\
\hline Pasteurization & $\mathrm{X}$ & - & - & $\mathrm{X}$ \\
\hline Process Heating & $\mathrm{X}$ & $\mathrm{X}$ & $\mathrm{X}$ & $\mathrm{X}$ \\
\hline Process Cooling & $\mathrm{X}$ & $\mathrm{X}$ & $\mathrm{X}$ & $\mathrm{X}$ \\
\hline Refrigeration & $\mathrm{X}$ & $\mathrm{X}$ & $\mathrm{X}$ & $\mathrm{X}$ \\
\hline Washing & $\mathrm{X}$ & $\mathrm{X}$ & $\mathrm{X}$ & $\mathrm{X}$ \\
\hline
\end{tabular}

Tab. 1. Heat sources ifour $\mathrm{n}$ different parts of the food sector 


\section{RESULTS}

Throughout the sector there are great similarities in technologies used and sources of waste heat. So it is legitimate to produce a model based on one part of the sector and later on apply it to other parts of the sector when optimizing the use of primary energy for providing for process heat.

Only parts of that waste heat produced in food industry can be recovered easily by implementation of an advanced HEN. A major part of the energy needs to be upgraded or converted to become useful due to its very low temperature levels.

Based on the findings illustrated in Fig. 1 a static model for the thermal busses was developed using ASPEN Hysys incorporating all sources, sinks and considered conversion and upgrading technologies. Fig. 2 shows a detailed view of the waste heat recovery model for the freezing compressors as shown in Fig. 1.

Definition of additional hydronic systems or extending the existing ones for cooling and heating can provide for a significant boiler load relief as well as reduction in electricity demand. In the base case, a maximum reduction of primary energy demand of $60 \%$ was estimated for the process running on full capacity.

Implementation of heat pumps between the hot and cold side of the hydronic system can help further upgrade their performance. Absorption refrigeration can only be applied using comparatively high waste heat stream temperatures.

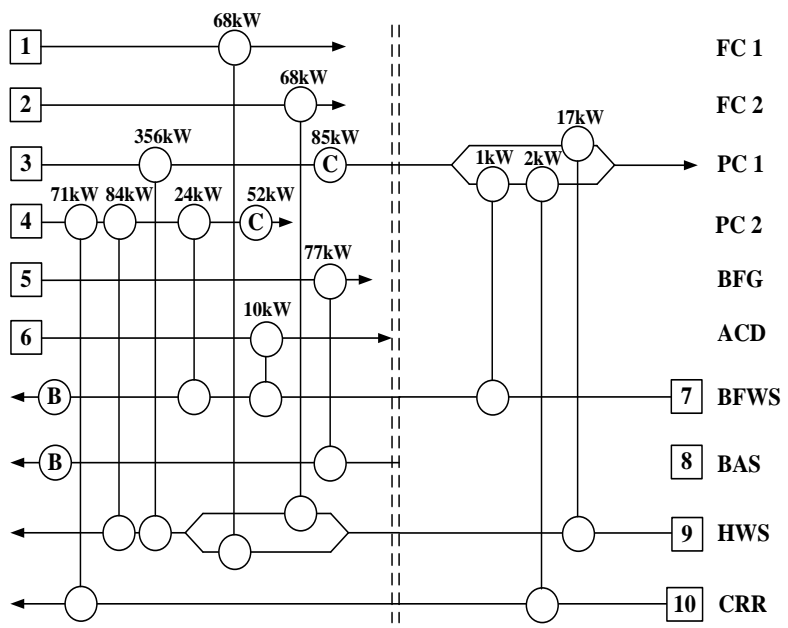

Fig.1. Grid Diagram of HEN Design (FC: Freezer Condenser; PC: Process Cooling; BFG: Boiler Flue Gas; ACD: Air Compressor Discharge; BFWS: Boiler Feed Water Supply; BAS: Boiler Air Supply; HWS: Hot Water Supply; CRR: Cold Room Refrigerator

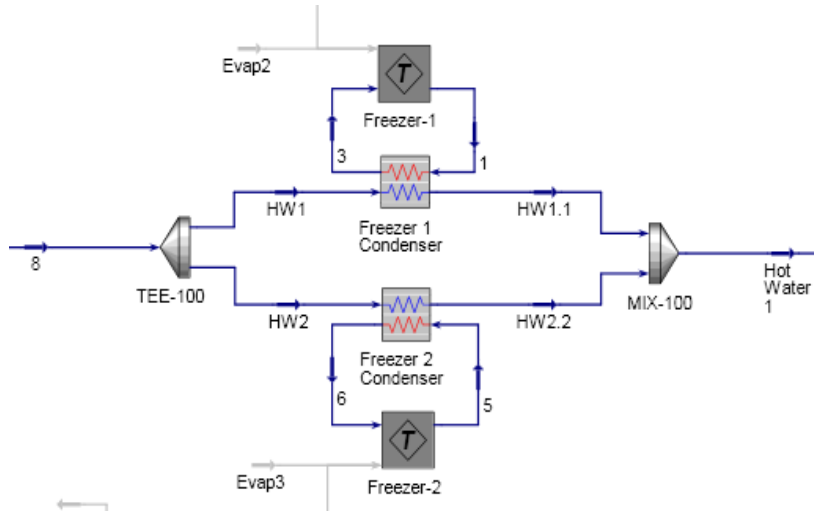

Fig. 2. Detailed view of the simulation of heat recovery from the freezing units
In all cases investigated parts of the production system could be run on hot or cold water or low pressure steam systems respectively. Unfortunately this would necessitate major modifications of the existing systems incurring significant cost.

\section{CONCLUSION}

The simulations carried out showed that the implementation of additional hydronic systems besides the steam network and refrigeration plants is potentially suitable to increase the overall energy efficiency of a production system in the food industry and therefore reduces primary energy use.

The principles are applicable across the whole sector with minimal alteration to the model, as sources and sinks can be modified to suit plant requirements.

Investment costs and technical integration are considered the major limitation to implementation of the system modifications proposed. Therefore realization of such systems would be most appropriate if a new site is planned.

For the work presented continuous production was assumed, possible product changes and existing thermal stores were not taken into account.

It is necessary to implement the production plan and therefore account for the changes in thermodynamic behavior of the system. The model needs to be further refined and additional data like product changes on the production lines taken into consideration. A dynamic model that takes the intermediate nature of the process into account will be developed to replace the static model.

\section{ACKNOWLEDGEMENTS}

This research is funded by the Engineering and Physical Sciences Research Council of the UK (EPSRC); and a fellowship within the Postdoc-Programme of the German Academic Exchange Service (DAAD).

\section{REFERENCES}

Ammar, Y.; Joyce, S.; Norman, R.; Wang, Y.D. \& Roskilly, A.P. (2011). Review of low grade thermal energy sources and uses from the process industry in the UK, Applied Energy, PRO-TEM Special Issue (in Press)

Atkins, M. J.; Walmsley, M .R. W. \& Neale, J. R. (2010). The challenge of integrating non-continuous processes - milk powder plant case study, Journal of Cleaner Production, Vol. 18, Nr. 9, (June 2010) pp 927-934

Bandyopadhyay, S.; Varghese, J. \& Bansal, V. (2010). Targeting for cogeneration potential through total site integration, Applied Thermal Engineering, Vol 30, Nr. 1, (January 2010) pp. 6-14

Dhole, V.R. \& Linnhoff, B. (1993). Total site targets for fuel, cogeneration, emissions, and cooling, Computers and Chemical Engineering, Vol. 17, Nr. 1, (January 1993) pp.101-109

HM Gouvernment (2008). Climate Change Act 2008: Chapter 27

Muller, D.C.A.; Marechal, F.M.A.; Wolewinski, T. \& Roux, P.J. (2007). An energy management method for the food industry, Applied Thermal Engineering, Vol. 27, Nr. 16, (November 2007) pp. 2677-2686

Reay, D.A. and Morrell, M.(2007) Overview of Process Heat Recovery, Carbon Trust

Söderman, J. \& Ahtila, P. (2010). Optimisation model for integration of cooling and heating systems in large industrial plants, Applied Thermal Engineering, Vol. 30 Nr. 1, (January 2010) pp. 15-22

Tuomaala, M.; Hurme, M. \& Leino, A.-M. (2010). Evaluating the efficiency of integrated systems in the process industry Case: Steam Cracker, Applied Thermal Engineering, Vol. 30, Nr. 1, (January 2010) pp. 45-52 